\title{
Ultimacy and alternative possibilities
}

\author{
John Martin Fischer
}

Published online: 24 March 2009

(C) The Author(s) 2009. This article is published with open access at Springerlink.com

\begin{abstract}
I explore a key feature of Robert Kane's libertarianism (about which I have been puzzled for some time). Kane claims that we should separate issues of alternative possibilities from issues of ultimacy, but he further argues that they are connected in a certain way. I call into question this connection, and I continue to argue for a strict separation of considerations pertaining to alternative possibilities and "actual-sequence" considerations.
\end{abstract}

Keywords Robert Kane - Alternative possibilities - Ultimate responsibility · Libertarianism

I have great admiration for Robert Kane's work on Free Will. I think that he has presented the most systematic, well worked out, and insightful defense of libertarianism, especially in its "positive" aspect. But there is a mystery right at the center of his theory; I have been puzzled by this aspect of Kane's views for some time, and this puzzling feature of his approach (perhaps, not surprisingly) emerges again in a salient way in Kane's contribution to Four Views on Free Will.

Kane distinguishes two different conditions that motivate libertarianism: the ultimacy condition (UR) and the alternative possibilities condition (AP). In my 1981 article, "Responsibility and Control," I essentially made a similar distinction, pointing out that some incompatibilists might grant that agents do not need alternative possibilities for moral responsibility, but still maintain that causal determinism rules out moral responsibility. ${ }^{1}$ Kane argues that the basic driving

1 Fischer (1981).

J. M. Fischer ( $₫)$

Department of Philosophy, University of California, HMNSS Building, Room 1604,

900 University Avenue, Riverside, CA 92521, USA

e-mail: John.Fischer@ucr.edu 
intuition of the libertarian is (UR). One might have expected then a crisp and clean separation of ultimacy and alternative possibilities. I prefer such a division of the conceptual landscape; after all, as I have recently learned in real life, tall fences make good neighbors. But Kane holds that the notion of ultimacy, properly understood, actually entails the existence of alternative possibilities for at least some actions. In his terms, UR entails AP (at least for some actions).

Kane points out that focusing on ultimacy might seem to leave no room for the traditional worries about alternative possibilities, and he continues as follows:

But does this mean that alternative possibilities or AP have nothing to do with free will? It might seem so, if one can argue directly for the incompatibility of free will and determinism from UR without mentioning alternative possibilities. But then what would become of the garden of 'forking paths' if alternative possibilities or AP are not required? Well, fortunately it turns out that AP and the garden of forking paths is relevant for free will after all. For, it can be shown that UR entails AP for at least some free actions. Why this is so is not obvious, but understanding it is also crucial, I believe, to fully understand the nature of free will. ${ }^{2}$

But how exactly does Kane argue that (UR) entails (AP)? Kane identifies the following "chain of inferences":

(1) free will entails (2) ultimate responsibility [UR] for our wills as well as for our actions, which entails (3) will-setting actions at some points in our lives, which in turn entails that some of our actions must satisfy (4) the plurality conditions. But if actions satisfy the plurality conditions and the agent could have done otherwise voluntarily, intentionally, and rationally, then the agent could have done otherwise; and so they had (5) alternative possibilities. Therein lies the connection between (UR) and (AP). ${ }^{3}$

An important point for Kane is that the relevant kind of freedom ("free will") requires "ultimate responsibility" not just for our actions, but also for our wills (which he identifies broadly as our characters and motivational states); further, Kane holds that such responsibility for our wills requires that we could have set them in a different way.

But I do not understand the argument. As far as I'm concerned, being the ultimate source of one's actions is a plausible candidate for a necessary condition for moral responsibility; of course, on my view, being the ultimate source (in the sense relevant to moral responsibility) does not entail indeterminism. Here I won't press on this point about the relationship between ultimacy and indeterminism; rather, I wish to show that nothing Kane says implies that ultimate sourcehood entails access to alternative possibilities.

To see my point, consider that one might lack alternative possibilities via two different routes. In the Frankfurt-cases, one lacks alternative possibilities with respect to action because of pre-emptive overdetermination; some failsafe device

\footnotetext{
${ }^{2}$ Fischer et al. (2007, pp. 16-17).

3 Fischer et al. (2007, p. 21).
} 
that doesn't actually play any role in the unfolding of the events leading to choice and action nevertheless is present and ensures the same choice and action (or that the agent lacks alternative possibilities with respect to choice and action). In other cases, some condition that intuitively threatens or perhaps rules out moral responsibility actually plays a role in the unfolding sequence of events and thereby precludes the agent's access to alternative possibilities. One can lack freedom to perform a different action (freedom to do otherwise) in virtue of the presence of a Frankfurt-style counterfactual intervener (the pre-emptive overdeterminer). Similarly, I believe that one can lack the freedom to set one's will in a different way in virtue of the presence of a Frankfurt-style counterfactual intervener. That is, the stage of will-setting is in this respect no different from the stage of action; in both cases alternative possibilities can be ruled out via the mere presence of the relevant sort of counterfactual intervener. So there is no difference between action and willsetting, as far as I can see, with respect to the fact that access to alternative possibilities can be ruled out in the "Frankfurt-style way"; of course, it can also be ruled out via the "actual-sequence way".

Now if this is correct, then I do not see how (UR) would entail (AP), or any plausible ultimate sourcehood condition would entail the requirement of access to alternative possibilities at any relevant point along the sequence. Of course, if there were only one way to block access to alternative possibilities with respect to the will, and this were the "actual-sequence way" - in which some actually operative or actually triggered event that intuitively threatens responsibility works to preclude access to alternative possibilities - then perhaps it would be tempting to suppose that ultimate responsibility requires access to alternative possibilities with respect to the will. But, as far as I can see, access to a different will- to a different character or motivational states - can be occluded via mere preemptive overdetermination, which does not in any way effect the story of how the relevant behavior unfolds. And, as Frankfurt put it, when a factor is in this way irrelevant to the explanation of behavior, it seems entirely gratuitous to assign it any weight or role in assessing moral responsibility for the behavior. The same point would seem to apply to ultimate sourcehood. How can the mere existence of a counterfactual intervenerwho plays no role in the sequence leading to the behavior and is thus irrelevant to the explanation of that behavior-affect whether the behavior issues from an agent as its ultimate source?

I do not see any argument in Kane that pre-emptive overdetermination cannot apply to the will. Nor does Kane argue that such over-determination is incompatible with ultimate sourcehood. In the absence of this sort of argumentation, Kane's "chain of inferences" falls apart, because there is simply no reason to accept that (3) entails (4): that will-setting actions require satisfaction of the plurality conditions.

Kane does seem to provide considerations that he takes to bolster the move from (3) will-setting to (4) plurality [AP]. He says:

... suppose that God created a world in which there is a lot of indeterminism of the kind that occurs in Austin-style examples. Chance plays a significant role, in human affairs as well as in nature. People set out to do things and often succeed, but sometimes they fail in the manner of Austin-style examples. They 
set out of kill prime ministers, hole putts, press buttons on coffee machines..., usually succeeding but sometimes failing by mistake or accident in ways that are undetermined.

Now imagine further that in this world all actions of all agents, whether they succeed in their purposes or not, are such that their reasons, motives and purposes for trying to act as they do are always predetermined or pre-set by God. ... Whether I press the button for coffee without cream, my wanting to do so because of my dislike of cream is predetermined by God; and so it is for all persons and all of their actions in this imagined world. Their reasons, motives and purposes for acting as they do are always predetermined by God.

I would argue that persons in such a world lack free will, even though it is often the case that they can do otherwise. in a way that is undetermined. The reason is that they can do otherwise, but only in the limited Austin-style way-by mistake or accident, unwillingly or unintentionally. What they cannot do in any sense is will otherwise than they do, for all of their reasons, motives and purposes have been pre-set by God.

The possibility of such worlds shows in a striking way why, to have free will, it is necessary not only to be the ultimate source of one's actions, but also to be the ultimate source of one's will to perform the actions. ${ }^{4}$

Kane finds it problematic, in the world he imagines, that all of the agents' reasons, motives, and purposes are "pre-set" or "pre-determined" by God. He further says that the reason why this is problematic is that, as a result of the predetermination of their wills, they cannot will to do otherwise-they do not have alternative possibilities with respect to their wills. But this argument is exasperating for various reasons.

First, I'm not sure exactly what God's "pre-determination" or "pre-setting" of the will consists in. Put slightly differently, exactly how does God pre-set the will of an agent? Does He do so by direct manipulation of the brain, like what might be envisaged on the part of a nefarious neurosurgeon? Or does He simply give the agent a "program" in advance that ensures that the agent will have a certain character and set of motivational states? Some might think that there is a significant difference between these (and perhaps other) ways of "pre-determining" or "presetting" the will; it is not obvious to me that an agent's freedom-even freedom of the will-is compromised by the latter way of "pre-setting" the will. After all, there are a couple of millennia of rather vigorous debates about this-and relatedissues!

But let us here simply grant, for the sake of the discussion, that both of these ways of "pre-determining" the will rule out alternative possibilities with respect to the will and also expunge ultimate sourcehood. Of course, it would not follow that all ways of ruling out alternative possibilities equally rule out ultimate sourcehood. After all, I have pointed out above that there are two different sorts of ways of ruling out alternative possibilities-via pre-emptive overdetermination and in the

\footnotetext{
$\overline{{ }^{4} \text { Fischer et al. (2007, pp. 18-19). }}$
} 
actual-sequence way. God's either directly manipulating agents or establishing a program that they must instantiate certainly would rule out alternative possibilities in the actual-sequence way, if these would rule out alternative possibilities at all. And thus it simply would not follow from an intuition that God's pre-setting an agent's will in either way would rule out ultimate sourcehood that a counterfactual intervener's precluding alternative possibilities would also rule out ultimate sourcehood.

Kane says (in the passage quoted above): "What [the individuals in the Austinworld] cannot do in any sense is will otherwise than they do, for all of their reasons, motives and purposes have been pre-set by God." In my view, Kane's mistake here is to move from an intuition that the individuals lack ultimate sourcehood because their wills have been pre-set by God to the conclusion that the reason they lack ultimate sourcehood is simply that the individuals cannot will otherwise (however this is accomplished). But this is certainly a gratuitous leap. Various other options for explaining the intuition are available: the agents' wills are not their own, they do not will freely, or perhaps they do not have guidance control of their wills. The most Kane is entitled to here, strictly speaking, is that when alternative possibilities with respect to the will are ruled out in the actual-sequence way, the agents are not the ultimate sources of their wills and actions. But it does not follow that ultimate sourcehood requires alternative possibilities.

Of course, my argumentation above presupposes that the Frankfurt-style counterfactual intervener does rule out alternative possibilities (of the relevant sort) with respect to actions. Then I go on to explore the question as to why the same sort of argumentation wouldn't call into question the requirement of alternative possibilities with respect to the will. I am obviously aware that there is considerable controversy about whether the Frankfurt-style preemptive overdetermination successfully deletes alternative possibilities, even in the case of action. Here I am putting these difficult questions aside, because I am focusing only on the argumentation presented by Kane in the book under discussion here, Four Views on Free Will.

But in fairness to Kane, he is a prominent defender of the "Dilemma Defense" of the Prinicple of Alternative Possibilities, which he applies to the context of the will in his landmark book, The Significance of Free Will..$^{5}$ According to Kane in this earlier book, in the Frankfurt cases one traces back to prior "self-forming" acts of will-setting, in which one (putatively) has alternative possibilities with respect to the will. Perhaps Kane will simply fall back on the argumentation in The Significance of Free Will, and rely on the Dilemma Defense argument to establish that ultimacy implies alternative possibilities for the will. If Kane makes this move, then our disagreement would focus on the Dilmma Defense; here I have sought to explore whether Kane offers a new argument-apart from the Dilemma Defense-for his contention that (UR) entails (AP).

Almost three decades ago (in "Responsibilty and Control"), I argued that we should separate questions about casual determinism's relationship to alternative possibilities from the issue of whether causal determination in the actual sequence is

\footnotetext{
5 Kane (1996).
} 
consistent with moral responsibility. I still think that it is analytically most perspicuous sharply and cleanly to distinguish the two issues: whether one has alternative possibilities, and whether the features of the actual-sequence are consistent with moral responsibility. Robert Kane has powerfully insisted that the fundamental engine driving libertarianism is the idea that we must be ultimate sources of our behavior, in order to be morally responsible. This suggests a sharp distinction between the role of ultimate sourcehood and alternative possibilities. I suppose that Kane could agree with me here, but nevertheless insist that there is an entailment between UR and AP. I have contended here that Kane has not provided any new argument in Four Views on Free Will-that is, an argument apart from the Dilemma Defense-that his UR entails AP. And I would suggest that this is a good thing, because it is better to draw a bright line between considerations about alternative possibilities and those pertaining to the actual sequence.

Acknowledgment I am grateful to Neal A. Tognazzini for comments on a previous version of this article.

Open Access This article is distributed under the terms of the Creative Commons Attribution Noncommercial License which permits any noncommercial use, distribution, and reproduction in any medium, provided the original author(s) and source are credited.

\section{References}

Fischer, J. M. (1981). Responsibility and control. Journal of Philosophy, 79, 24-40. Kane, R. (1996). The significance of free will. New York: Oxford University Press. Fischer, J. M., et al. (2007). Four views on free will. Oxford: Blackwell Publishing. 